\title{
Conmemoración del trigésimo aniversario del edificio de El Colegio de México*
}

\section{Gustavo Garza**}

La Ciudad de México, como cualquier metrópoli, sólo es científicamente comprensible al visualizar la interacción de su dimensión demográfica, urbanística, ecológica, económica y política con su estructura de formas, relaciones, conductas y organizaciones sociales. El andamiaje espacial resultante constituye un conjunto sistémico indispensable para descifrar las categorías que explican la evolución de las naciones dentro de la denominada revolución terciaria.

La trama metropolitana se teje por la acción de los agentes públicos y privados que van reproduciendo un conjunto de usos de suelo y equipamiento de la ciudad en forma más o menos ordenada, dependiendo del rigor de la normatividad urbanística existente. Las metrópolis en la emergente sociedad del conocimiento tienden a favorecer los ensambles educativos que se transforman en verdaderos factores de producción, indispensables para el progreso de la sociedad y la posibilidad de insertarse en forma competitiva en una economía de escala planetaria.

\section{Ciudad metropolitana y polígono científico}

En 1950 la población de la Ciudad de México era de 2.9 millones, distribuida en un tejido urbano de 23 mil hectáreas; constituía la vigésima concentración más grande del mundo. Estaba formada por $11 \mathrm{de}$ las 16 delegaciones actuales, y en la década de los cincuenta inició su proceso de metropolización al extenderse hacia el municipio de Tlalnepantla, Estado de México.

En esos años había una significativa dispersión de los edificios de la Universidad Nacional Autónoma de México dentro de la trama de la ciudad, aunque la mayoría de ellos se localizaba en el centro. Ante

* Texto leído en la ceremonia de conmemoración del trigésimo aniversario del edificio de El Colegio de México en el Ajusco, 28 de septiembre de 2006.

** Profesor investigador del Centro de Estudios Demográficos, Urbanos y Ambientales de El Colegio de México. Correo electrónico: ggarza@colmex.mx.

ESTUDIOS DEMOGRÁFICOS Y URBANOS, VOL. 22, NÚM. 1 (64), PP. 219-222 
la influencia de las propuestas arquitectónicas de Le Corbusier, surgió la idea de construir una ciudad universitaria. Tras una serie de debates al respecto, se decidió que el terreno más adecuado estaba en el sur de la ciudad, al lado opuesto de la avenida Insurgentes, donde se urbanizaba el actual Pedregal de San Ángel. En un concurso de proyectos arquitectónicos para la futura ciudad universitaria, ganó la propuesta de un grupo de estudiantes integrado por Armando Franco, Teodoro González de León y Enrique Molinar; fue incorporada al plan maestro de Mario Pani y Enrique del Moral. La construcción de tan relevante obra avanzó muy favorablemente y la Ciudad Universitaria fue inaugurada el 20 de noviembre de 1952.

Este histórico proyecto nos proporciona dos antecedentes relevantes para entender la futura ubicación y la silueta arquitectónica del majestuoso edificio de El Colegio de México, construido 24 años después de la Ciudad Universitaria y cuyo trigésimo aniversario nos congrega en esta celebración: el primero es un punto cardinal, el sur de la Ciudad de México; el segundo un joven arquitecto, Teodoro González de León. Se me ha solicitado sintetizar el vínculo de la expansión de la ciudad con la construcción y localización de nuestro edificio, pues sobre la brillante trayectoria del arquitecto ya plenamente consagrado hablará Javier Garciadiego.

\section{Consolidación del sur como área científica y humanística}

En 1970 la Zona Metropolitana de la Ciudad de México tenía 8.6 millones de habitantes y se había expandido en las 16 delegaciones del Distrito Federal y en 11 municipios del Estado de México; había subido al quinto rango entre las grandes urbes del planeta. En 1976, año en que se inauguró nuestro edificio, se puede estimar que la ciudad había alcanzado 11 millones de personas.

En los años setenta, precisamente, la Ciudad de México inició una segunda etapa de metropolitanismo cuando las delegaciones y municipios del primer contorno que circunda a las delegaciones centrales evidenciaron un mayor dinamismo demográfico y urbanístico, siendo que el desplazamiento hacia el sur prosiguió de Coyoacán, delegación donde se ubica la Ciudad Universitaria, hacia Tlalpan.

En 1970 Tlalpan tenía 130 mil habitantes y alcanzó 240 mil en 1976, cuando El Colegio de México inició sus actividades en esta sede. Desde entonces la delegación redujo su crecimiento principalmente 
porque más de $70 \%$ de su territorio es de preservación ecológica. No obstante, concentraba 610 mil personas en 2005.

La población total de la delegación se multiplicó por 2.5 durante los 30 años de existencia de nuestro edificio, pero buena parte de dicha expansión ha sido hacia la carretera del Ajusco. Esto explica las complicaciones viales que experimentamos en la actualidad, pero al mismo tiempo hace posible que se tenga acceso a una serie de funciones urbanas de las que no se disponía en los años setenta.

Importa destacar, sin embargo, el proceso de prolongación del equipamiento cultural de Coyoacán hacia Tlalpan. El Colegio es la edificación pionera dentro del área de instituciones académicas del Camino al Ajusco; se construyeron con posterioridad el Fondo de Cultura Económica, la Universidad Pedagógica Nacional, la Facultad Latinoamericana de Ciencias Sociales y, desafortunadamente - por los problemas viales que ocasiona-, un colegio particular en el edificio donde se encontraba la Fundación de Estudios Prospectivos Javier Barros Sierra.

Adicionalmente a este núcleo académico contiguo, en la misma delegación de Tlalpan se ubican el Campus Ciudad de México del Tecnológico de Monterrey, así como la sede principal del Centro de Investigaciones y Estudios Superiores de Antropología Social (CIESAS). En la delegación vecina de Coyoacán se localiza la Universidad Autónoma Metropolitana-Xochimilco, mientras en Álvaro Obregón se encuentra el Campus Río Hondo del Instituto Tecnológico Autónomo de México, y en La Magdalena Contreras el Campus Santa Teresa.

La zona sur de la Ciudad de México, en síntesis, está dotada del mayor equipamiento de investigación y docencia no sólo de la metrópoli, sino de cualquier ciudad del país y probablemente de América Latina. La localización de El Colegio de México en este cardinal polígono científico y cultural ha sido un verdadero acierto, pues le representa importantes sinergias en la realización de sus actividades de docencia, investigación y difusión.

\section{El edificio como andamiaje institucional}

El inmueble de El Colegio de México es crucial para el desempeño de las tareas sustantivas de la institución, por lo que su preservación debe ser atendida cuidadosamente, al igual que la funcionalidad de sus oficinas, cubículos, equipo y mobiliario. 
Una visión prospectiva de El Colegio de México al 2030 tendrá que considerar la expansión de su edificio. En un futuro inmediato es prioritaria la ampliación de la biblioteca y del área de estacionamiento. En el mediano plazo será necesario evaluar la adecuación del inmueble a la dinámica institucional derivada de los crecientes requerimientos de desarrollo de las ciencias sociales y las humanidades en México. Esto es indispensable para poder enfrentar exitosamente los presentes y futuros retos del país. Igualmente habrá que avanzar hacia el concepto de edificio inteligente que demandará una sociedad telemática cada vez más compleja.

La futura cristalización de estos proyectos será el mejor tributo a las tres décadas de existencia del monumental espacio arquitectónico de El Colegio de México, el cual es consustancial a nuestra institución. 